\title{
KENDALA PELAKSANAAN PROGRAM JKN TERKAIT PENERIMAAN PASIEN, PENGOLAHAN DATA MEDIS, PELAPORAN, DAN PENDANAAN JKN DI PUSKESMAS GONDOKUSUMAN II YOGYAKARTA
}

\author{
Nuryati ${ }^{1}$, Savitri Citra Budi' ${ }^{2}$, dan Nur Rokhman ${ }^{2}$

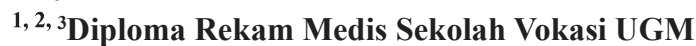 \\ nur3yati@yahoo.com ${ }^{1}$
}

\begin{abstract}
The purpose of this study was to determine the general picture and constraints related to the implementation of the program JKN admissions, medical data processing, reporting and funding JKN in Puskesmas Gondokusuman II. The research is a qualitative descriptive and cross-sectional study design. Results showed that patients JKN reception starts from taking a queue number, then checking membership data, identification of other social identities, social data entry into a P-Care and SIMPUS and deliver medical records to the clinic. With the entry of data to be socially into P-Care and SIMPUS the time service is also getting old. JKN patient medical data processing is done with the patient's medical data entry into a P-Care and SIMPUS. However, not all patient medical data can be entry into a P-Care. Reporting JKN program consists of 10 visit reports and report diseases based on the type of membership JKN patients, namely Askes, JAMKESMAS and BPJS Mandiri. The report was sent to the City Health Office Yogyakarta each month. Funding JKN programs are of two kinds, namely based on capitation and non capitation. For capitation, health centers receive pembayarannny every month. As for the non capitation funding, has not been running. JKN program implementation constraints related admissions, medical data processing, reporting and financing activities consisted of the elements of man, materials, machines, methods, markets and money.
\end{abstract}

Keywords: JKN program , Patient Admissions, Medical Data Processing, Reporting , Funding

\begin{abstract}
Abstrak
Tujuan penelitian ini adalah mengetahui gambaran umum dan kendala pelaksanaan program JKN terkait penerimaan pasien, pengolahan data medis, pelaporan dan pendanaan JKN di Puskesmas Gondokusuman II. Jenis penelitian ini adalah deskriptif kualitatif dengan rancangan penelitian cross-sectional. Hasil penelitian menunjukkan bahwa penerimaan pasien JKN dimulai dari pengambilan nomor antrian, kemudian pengecekkan data kepesertaan, indentifikasi identitas sosial lainnya, entry data sosial ke dalam P-Care dan SIMPUS serta mengantarkan rekam medis ke balai pengobatan. Dengan harus entry data sosial ke dalam P-Care dan SIMPUS maka waktu pelayanannya juga semakin lama. Pengolahan data medis Pasien JKN dilakukan dengan entry data medis pasien ke dalam P-Care dan SIMPUS. Namun, belum semua data medis pasien dapat di-entry ke dalam P-Care. Pelaporan program JKN terdiri dari laporan kunjungan dan laporan 10 besar penyakit berdasarkan jenis kepesertaan pasien JKN, yakni Askes, Jamkesmas dan BPJS Mandiri. Laporan tersebut dikirim ke Dinkes Kota Yogyakarta setiap bulan. Pendanaan program JKN ada dua macam, yakni berdasarkan kapitasi dan non kapitasi. Untuk kapitasi, Puskesmas menerima pembayarannnya setiap bulan. Sedangkan untuk pendanaan non kapitasi, belum berjalan. Kendala pelaksanaan program JKN terkait penerimaan pasien, pengolahan data medis, pelaporan dan pendanaan terdiri dari unsure man, materials, machines, methods, markets dan money.
\end{abstract}

Kata Kunci: Program JKN, Penerimaan Pasien, Pengolahan Data Medis, Pelaporan, Pendanaan. 


\section{PENDAHULUAN}

Dalam upaya pembangunan kesehatan di Indonesia, Pemerintah menyelenggarakan Program JKN. Berdasarkan Perpres RI Nomor 12 tahun 2013 tentang Jaminan Kesehatan, Jaminan Kesehatan adalah jaminan berupa perlindungan kesehatan agar peserta memperoleh manfaat pemeliharaan kesehatan dan perlindungan dalam memenuhi kebutuhan dasar kesehatan yang diberikan kepada setiap orang yang telah membayar iuran atau iurannya dibayar oleh pemerintah.

Mulai 1 Januari 2014, Jaminan Kesehatan Nasional diselenggarakan di Indonesia. Program JKN diselenggarakan oleh BPJS Kesehatan. BPJS kesehatan merupakan tranformasi dari PT Askes, yang sebelumnya telah lebih dulu menjadi penyelenggara jaminan kesehatan bagi masyarakat Indonesia. Menurut Perpres RI Nomor 12 tahun 2013 tentang Jaminan Kesehatan, BPJS Kesehatan adalah badan hukum yang dibentuk untuk menyelenggarakan program Jaminan Kesehatan.

Berdasarkan Permenkes RI Nomor 71 Tahun 2013 tentang Jaminan Kesehatan, pelayanan kesehatan bagi Peserta yang dijamin oleh BPJS Kesehatan terdiri atas Pelayanan Kesehatan Tingkat Pertama dan Pelayanan Kesehatan Rujukan Tingkat Lanjutan, Pelayanan kesehatan bagi Peserta dilaksanakan secara berjenjang sesuai kebutuhan medis dimulai dari Fasilitas Kesehatan tingkat pertama. Sebagaimana tercantum dalam Permenkes RI Nomor 71 Tahun 2013 tentang Pelayanan Kesehatan Pada Jaminan Kesehatan Nasional, fasilitas kesehatan tingkat pertama dapat berupa Puskesmas atau yang setara, praktik dokter, praktik dokter gigi, klinik pratama atau yang setara dan Rumah Sakit Kelas D Pratama atau yang setara.

Sebagai salah satu fasilitas pelayanan kesehatan tingkat pertama dalam penyelenggaraan jaminan kesehatan nasional, peran Puskesmas sangatlah besar, termasuk Puskesmas Gondokusuman II. Menurut Kemenkes RI (2014), Puskesmas merupakan salah satu fasilitas kesehatan tingkat pertama di satu wilayah kecamatan atau sebagian wilayah kecamatan akan difungsikan sebagai gate keeper dari salah satu sistem penyelenggaraan pelayanan kesehatan perorangan yang dikelola oleh BPJS Kesehatan. Puskesmas akan difungsikan dalam proses penjaringan pasien agar pelayanan kesehatan perseorangan dapat diberikan secara benar dan tepat sesuai dengan tingkat kebutuhannya.
Sebelum dimulainya program JKN, BPJS Kesehatan pernah melakukan sosialisasi mengenai tata cara pelaksanaannnya fasilitas pelayanan kesehatan yang bekerja sama dengan BPJS Kesehatan, termasuk Puskesmas. Namun, sosialisasi itu tidak diikuti dengan komunikasi yang terus menerus antara Puskesmas dengan BPJS Kesehatan, sehingga terkadang ada ketentuan baru dalam pelaksanaan JKN yang tidak segera diketahui oleh Puskesmas.

Apalagi sejak berjalannya program JKN ini ada peraturan yang berubah dan juga peraturan tambahan yang ditetapkan setelah tanggal 1 Januari 2014. Misalnya, pedoman pelaksanaan program JKN baru diundangkan dan berlaku pada 25 Juni 2014, standar tarif pelayanan kesehatan dalam penyelenggaraan JKN yang berlaku mulai 1 September 2014. Dengan adanya peraturan baru yang berkaitan dengan pelaksanaan JKN, BPJS Kesehatan dan Dinas Kesehatan Kota Yogyakarta telah memperbarui perjanjian kerjasama mengenai pelayanan kesehatan tingkat pertama pada Puskesmas di kota Yogyakarta sebanyak 4 kali dan yang terakhir dilakukan pada bulan November 2014. Puskesmas diharapkan untuk menjalankan Program JKN sesuai dengan peraturan yang berlaku.

Dengan adanya peraturan yang berubah-ubah dan juga kurangnya komunikasi antara Puskesmas dengan BPJS Kesehatan, memungkinkan terjadinya permasalahan di Puskesmas sebagai pelaksana program JKN yang berhubungan langsung dengan pasien. Apalagi Program JKN bisa dikatakan program yang masih baru, Puskesmas juga masih terus berusaha untuk menyesuaikan pelaksanaan Program JKN dengan segala perubahan aturan yang ada.

Tujuan dari penelitian ini adalah sebagai berikut.

1. Mendiskripsikan pelaksanaan Program JKN di Puskesmas Gondokusuman II terkait penerimaan pasien, pengolahan data medis, pelaporan dan pendanaan.

2. Mengetahui kendala pelaksanaan Program JKN di Puskesmas Gondokusuman II, terkait penerimaan pasien, pengolahan data medis, pelaporan dan pendanaan.

\section{Puskesmas}

Berdasarkan Permenkes RI Nomor 75 Tahun 2014 Tentang Pusat Kesehatan Masyarakat, yang dimaksud dengan Pusat Kesehatan Masyarakat yang selanjutnya disebut Puskesmas adalah fasilitas pelayanan kesehatan yang menyelenggarakan 
upaya kesehatan masyarakat dan upaya kesehatan perseorangan tingkat pertama, dengan lebih mengutamakan upaya promotif dan preventif, untuk mencapai derajat kesehatan masyarakat yang setinggi-tingginya di wilayah kerjanya.

\section{Pelaksanaan Jaminan Kesehatan Nasional}

Menurut Sabarguna (2007), pelaksanaan adalah proses, cara, pembuatan, melaksanakan sesuai dengan rancangan dan keputusan (kesepakatan). Kejelasan yang pokok sebagai dasar pelaksanaan program adalah kejelasan apa yang akan dimonitor, dapat berpartisipasi aktif walaupun disadari sepenuhnya penentuan indikator dan di kembangkannya secara bertahap yang mempengaruhi cara pelaksanaan dan pelaksana yang melakukan program.

Berdasarkan Perpres RI Nomor 12 Tahun 2013 tentang Jaminan Kesehatan, Jaminan Kesehatan adalah jaminan berupa perlindungan kesehatan agar peserta memperoleh manfaat pemeliharaan kesehatan dan perlindungan dalam memenuhi kebutuhan dasar kesehatan yang diberikan kepada setiap orang yang telah membayar iuran atau iurannya dibayar oleh pemerintah.

Berdasarkan Permenkes RI Nomor 28 Tahun 2014 tentang Pedoman Pelaksanaan Program Jaminan Kesehatan Nasional, penyelenggaraan jaminan kesehatan nasional mengacu pada prinsip-prinsip Sistem Jaminan Sosial Nasional (SJSN) yaitu:

a. Dana amanat dan nirlaba dengan manfaat untuk semata-mata peningkatan derajat kesehatan masyarakat.

b. Menyeluruh (komprehensif) sesuai dengan standar pelayanan medik yang cost effective dan rasional.

c. Pelayanan terstruktur, berjenjang dengan portabilitas dan ekuitas.

d. Efisien, transparan dan akuntabel.

Berdasarkan Permenkes RI Nomor 28 tahun 2014 tentang Pedoman Pelaksanaan Program Jaminan Kesehatan Nasional, tujuan pelaksanaan program Jaminan Kesehatan Nasional (JKN) untuk memberikan perlindungan kesehatan dalam bentuk manfaat pemeliharaan kesehatan dalam rangka memenuhi kebutuhan dasar kesehatan yang diberikan kepada setiap orang yang telah membayar iuran atau iurannya dibayar oleh pemerintah. Unsur-unsur penyelenggaraan dalam Jaminan Kesehatan Nasional meliputi regulator, peserta program JKN, pemberi pelayanan kesehatan dan badan penyelenggara.

\section{Regulator}

Yang meliputi berbagai kementerian/lembaga terkait antara lain Kementerian Koordinator Kesejahteraan Rakyat, Kementerian Kesehatan, Kementerian Keuangan, Kementerian Sosial, Kementerian Tenaga Kerja dan Transmigrasi, Kementerian Dalam Negeri, dan Dewan Jaminan Sosial Nasional (DJSN).

\section{Peserta Program Jaminan Kesehatan Nasional (JKN)}

Peserta Program Jaminan Kesehatan Nasional (JKN) adalah seluruh penduduk Indonesia, termasuk orang asing yang bekerja paling singkat 6 (enam) bulan di Indonesia, yang telah membayar iuran.

\section{Pemberi Pelayanan Kesehatan}

Pemberi Pelayanan Kesehatan adalah seluruh fasilitas layanan kesehatan primer (Fasilitas Kesehatan Tingkat Pertama) dan rujukan (Fasilitas Kesehatan Rujukan Tingkat Lanjut).

\section{Badan Penyelenggara}

Badan Penyelenggara adalah badan hukum publik yang menyelenggarakan program jaminan kesehatan sebagaimana yang ditetapkan oleh Undang-Undang Nomor 24 Tahun 2011 tentang Badan Penyelenggara Jaminan Sosial (BPJS).

Berdasarkan Peraturan Menteri Kesehatan Nomor 71 tahun 2013 Tentang Jaminan Kesehatan pelayanan kesehatan tingkat pertama diatur dalam pasal 16 , pasal 17, pasal 18, pasal 19.

\section{Sumber Daya Manusia}

Berdasarkan Permenkes RI Nomor 75 Tahun 2014 tentang Puskesmas, sumber daya manusia yang ada di Puskesmas diatur pada pasal 16.

\section{P-Care}

P-Care (Primary Care) merupakan sistem informasi pelayanan pasien yang ditujukan bagi pasien yang menjadi peserta BPJS berbasis komputer dan internet. P-Care ditujukan bagi pelayanan primer (Puskesmas) dan didalamnya melakukan pengolahan data mulai dari pendaftaran, penegakan diagnosis, 
pemberian terapi hingga pemeriksaan laboratorium. $P$-Care ini dikembangkan oleh PT Askes dan merupakan pengembangan dari aplikasi pelayanan kesehatan. Diharapkan dengan adanya P-Care, semua data kesehatan yang berhubungan dengan pelayanan pasien bersifat realtime, terintergrasi dari setiap bagian di suatu institusi pelayanan kesehatan (Siagian, 2014).

\section{Simpus}

Sistem Informasi Manajemen Puskesmas (SIMPUS) adalah suatu tatanan manusia dan atau peralatan yang menyediakan informasi untuk membantu proses manajemen Puskesmas untuk mencapai sasaran kegiatannya. SIMPUS merupakan sebuah sistem informasi yang terintegrasi dan didesain multi user yang disiapkan untuk menangani keseluruhan proses manajemen Puskesmas. SIMPUS merupakan suatu perangkat lunak atau dalam istilah komputer adalah software yang fungsi utamanya untuk mengolah data pasien yang berkunjung ke Puskesmas (Banunaek, 2014).

\section{Penerimaan Pasien JKN}

Tempat penerimaan pasien rawat jalan adalah unit pelayananan penerimaan dan pendaftaran pasien yang akan berlangsung ke poliklinik pada suatu rumah sakit. Disinilah pelayanan pertama kali diterima oleh seorang pasien saat tiba di rumah sakit. Seorang pasien akan merasakan kesan baik apabila mendapat pelayanan yang ramah, sopan, bertanggungjawab dan lain-lain (Depkes RI, 1997).

Menurut Budi (2011), tempat penerimaan pasien merupakan gerbang pertama di suatu fasilitas pelayanan kesehatan. Beberapa pasien memutuskan untuk berobat ke di suatu fasilitas pelayaan kesehatan dengan mempertimbangkan tempat penerimaan pasien yang nyaman dan petugas yang memuaskan. Untuk jenis penerimaan pasien di fasilitas pelayanan kesehatan ada yang disebut pasien baru dan pasien lama. Pasien baru berarti bahwa pasien tersebut belum pernah belum pernah melakukan kunjungan ke fasilitas pelayanan kesehatan tersebut atau pasien tersebut baru pertama kali datang berobat ke fasilitas pelayanan tersebut. Untuk pasien lama merupakan pasien yang pernah berobat di fasilitas pelayanan kesehatan tertentu.
Menurut IFHIMA (2012), aspek yang penting dari pendaftaran pasien adalah:

a. Ketika seorang datang ke rumah sakit atau klinik untuk pertama kalinya, mereka harus terdaftar sebagai pasien baru. Namun untuk memastikan bahwa pasien adalah pasien baru maka harus ditanya apakah mereka pernah ke rumah sakit atau klinik sebelumnya. Bahkan jika mereka mengatakan tidak, staf klinik masih harus memeriksa pasien dalam database komputer di fasilitas itu, indek utama pasien atau dengan bagian rekam kesehatan, tergantung pada tingkat komputerisasi di fasilitas itu. Langkah ini diperlukan untuk memastikan bahwa pasien tidak ada sejumlah rekam kesehatan dirumah sakit atau klinik dan untuk memastikan bahwa tidak ada duplikasi rekam kesehatan.

b. Jika pasien belum mempunyai sejumlah rekam kesehatan, maka pasien terdaftar dan nomor identifikasi pasien diberikan. Di sebagian besar rumah sakit dan pusat kesehatan, nomor registrasi ini digunakan sebagai nomor rekam kesehatan pasien.

c. Jika pasien memiliki data yang ada diindeks utama pasien dan sejumlah rekam kesehatan, informasi yang baru harus diperiksa dengan data sebelumnya dan perubahan dicatat.

\section{Pengolahan Data Medis}

Menurut Rustiyanto (2010), data adalah ciri/ karakterisktik, informasi/ fakta yang mengandung arti kebenaran. Sedangkan menurut Hatta (2011), data diperoleh melalui pencatatan (recording) terhadap berbagai hal di institusi layanan kesehatan ataupun dari survei/ riset/ penelitian. Pada prinsipnya data adalah hasil pengukuran (measurement) terhadap karakteristik yang diteliti, yaitu sesuatu yang bisa berupa kegiatan atau kejadian, atau ciri tertentu. Pengukuran dapat dilakukan baik melalui perhintungan, misalnya jumlah wanita ber-KB, atau melalui pengukuran dengan alat pengukuran berat badan. Secara umum pengukuran tersebut diperoleh melalui pengamatan atau observasi.

Data medis didapatkan setelah pasien mendapat pemeriksaan dari tenaga kesehatan (Budi, 2011). Menurut Rustiyanto (2010), pengolahan data yaitu suatu kegiatan untuk menyusun data yang diperoleh seluruhnya menjadi suatu susunan yang dapat dianalisa dan ditarik kesimpulan. Pengolahan data dapat dilakukan dengan menggunakan tangan 
(manual) maupun mempergunakan alat elektronik, sehingga akan menghasilkan keluaran (output) yang dapat berbentuk tabel, grafik atau ringkasan seperti jumlah angka rata-rata, prosentase dan sebagainya.

\section{Pelaporan Program JKN}

Pelaporan adalah salah satu fungsi manajemen berupa penyampaian pengembangan atau hasil kegiatan atau pemberian keterangan mengenai segala hal yang bertalian dengan tugas dan fungsi-fungsi kepada pejabat yang lebih tinggi, baik secara lisan secara tulisan (Rusdiana, 2014).

Menurut Sumarto dan Dwiantara (2000), laporan memiliki berbagai macam kegunaan dan mungkin sekali dari masing-masing kegunaan tersebut saling berkaitan satu sama lain. Adapun beberapa manfaat tersebut antara lain:

a. Sebagai sarana komunikasi vertikal

b. Sebagai alat pertanggungjawaban

c. Memberikan informasi penting.

d. Sebagai bahan untuk pengambilan keputusan

\section{Pendanaan Program JKN}

Pembiayaan kesehatan atau lebih tepatnya disebut pendanaan kesehatan merupakan suatu cara dalam memungkinkan seseorang memenuhi kebutuhan medisnya (Hatta, 2011). Berdasarkan Permenkes RI Nomor 59 Tahun 2014 Tentang Standar Tarif Pelayanan Kesehatan Dalam Penyelenggaraan Program Jaminan Kesehatan, tarif pelayanan pada Fasilitas Kesehatan Tingkat Pertama meliputi tarif kapitasi dan tarif non kapitasi. Tarif kapitasi adalah besaran pembayaran per-bulan yang dibayar dimuka oleh BPJS Kesehatan kepada Fasilitas Kesehatan Tingkat Pertama berdasarkan jumlah peserta yang terdaftar tanpa memperhitungkan jenis dan jumlah pelayanan kesehatan yang diberikan. Tarif non kapitasi adalah besaran pembayaran klaim oleh BPJS Kesehatan kepada Fasilitas Kesehatan Tingkat Pertama berdasarkan jenis dan jumlah pelayanan kesehatan yang diberikan.

\section{Kendala Pelaksanaan JKN}

Menurut Depdiknas (2008), kendala diartikan sebagai halangan; rintangan; gendala; Man faktor atau keadaan yang membatasi, menghalangi, atau mencegah pencapaian sasaran; kekuatan yang memaksa pembatalan pelaksanaan; mengendalakan menghalangi; merintangi; menggendalakan.
Menurut Manullang dalam Rusdiana (2014), mengkategorikan sumber-sumber penyebab berdasarkan prinsip 6M yaitu man, materials, machines, methods, markets dan money.

\section{METODE PENELITIAN}

Jenis penelitian deskriptif dengan pendekatan kualitatif. Rancangan penelitian dengan Cross sectional survey. Subyek penelitian ini adalah 3 Petugas Penerimaan Pasien JKN, 4 Petugas Pengolahan Data Medis Pasien JKN dan 1 Administrator BPJS. Obyek penelitian ini adalah kegiatan pelaksanaan JKN terkait penerimaan pasien, pengolahan data medis, pelaporan dan pendanaan. Pengumpulan data dengan cara wawancara, observasi dan studi dokumentasi.Instrumen penelitian untuk pengumpulan data dalam penelitian ini adalah pedoman wawancara, checklist observasi, dan checklist Studi Dokumentasi. Analisis penelitian kualitatif terdiri dari 3 tahap, yaitu: reduksi data, penyajian data, penarikan kesimpulan

Kesimpulan dalam penelitian kualitatif merupakan temuan baru yang sebelumnya belum pernah ada. Temuan dapat berupa deskripsi atau gambaran suatu objek yang sebelumnya masih remang-remang atau gelap sehingga setelah diteliti menjadi jelas, dapat berupa hubungan kausal atau interaktif, hipotesis atau teori. Kesimpulan awal yang dikemukakan masih bersifat sementara dan akan berubah jika tidak ditemukan bukti-bukti yang kuat yang mendukung pada tahap pengumpulan data berikutnya.

Penarikan kesimpulan dalam penelitian akan dilakukan setelah analisis dan pembahasan yang merupakan temuan baru yang sebelumnya belum pernah ada yang merupakan hasil dari analisis berdasarkan tujuan penelitian. Data yang akan diolah pada penelitian ini merupakan data dari hasil wawancara, observasi dan studi dokumentasi.

\section{HASIL DAN PEMBAHASAN}

Pelaksanaan Program Jaminan Kesehatan Nasional Di Puskesmas Gondokusuman II Terkait Penerimaan Pasien, Pengolahan Data Medis, Pelaporan Dan Pendanaan.

\section{Penerimaan pasien JKN}

Berdasarkan observasi yang dilakukan peneliti, diketahui bahwa penerimaan pasien di Puskesmas 
Gondokusuman II menggunakan satu loket pendaftaran. Loket pendaftaran tidak dibedakan antara pasien JKN dan pasien non JKN. Tidak ada petugas khusus untuk melayani pendaftaran pasien JKN. Semua petugas bisa melayani pendaftaran pasien JKN. Petugas penerimaan pasien di Puskesmas Gondokusuma II berjumlah 4 orang.

Menurut Budi (2011), tempat penerimaan pasien merupakan gerbang pertama di suatu fasilitas pelayanan kesehatan. Beberapa pasien memutuskan untuk berobat ke di suatu fasilitas pelayaan kesehatan dengan mempertimbangkan tempat penerimaan pasien yang nyaman dan petugas yang memuaskan. Sedangkan menurut Agustina (2010), tempat penerimaan pasien rawat jalan (TPPRJ) disebut juga loket pendaftaran rawat jalan atau sebagai pintu awal pasien masuk atau kontak pertama kali pasien datang ke rumah sakit. Begitu juga yang di Puskesmas Gondokusuman II, dalam pelaksanaan Program JKN di tempat pendaftaran merupakan kontak awal pasien dengan Puskesmas.

Pengecekkan kepesertaan dilakukan petugas untuk memastikan apakah pasien sudah terdaftar sebagai peserta JKN atau belum. Pengecekkan ini dilakukan dengan memasukkan NIK ke dalam aplikasi P-Care. Pengecekkan NIK ini dikhususkan untuk pasien yang merupakan penduduk dalam kota Yogyakarta. Jika penduduk dalam kota Yogyakarta sudah terdaftar sebagai peserta JKN, maka pasien tidak bisa menggunakan jaminan KTP untuk berobat. Identitas sosial pasien JKN yang dicatat pada resep obat berupa nama pasien, alamat, nomor rekam medis, tanggal kunjungan, balai pengobatan tujuan, nomor jaminan dan jenis kepesertaan JKN. Hal di atas juga sesuai dengan hasil observasi berikut ini.

Entry data sosial ke dalam $P$-Care dilakukan dengan cara memasukkan nomor kepesertaan pasien JKN dan tujuan kunjungan pasien JKN. Untuk pasien baru, entry data sosial ke dalam SIMPUS dilakukan dengan cara memasukkan nomor rekam medis, nama, alamat, jenis jaminan, nomor jaminan, umur, jenis kelamin, tujuan kunjungan dan cara bayarnya untuk pasien baru. Sedangkan untuk pasien lama, cukup memasukkan nomor rekam medis, tujuan kunjungan, cara bayarnya. Hal ini memerlukan waktu yang lebih lama dalam penerimaan pasien JKN, karena harus entry data sosial yang hampir sama ke dalam dua aplikasi yang berbeda.

\section{Pengolahan Data Medis Pasien JKN}

Rustiyanto (2010), pengolahan data yaitu suatu kegiatan untuk menyusun data yang diperoleh seluruhnya menjadi suatu susunan yang dapat dianalisa dan ditarik kesimpulan. Pengolahan data dapat dilakukan dengan menggunakan tangan (manual) maupun mempergunakan alat elektronik.

P-Care (Primary Care) merupakan sistem informasi pelayanan pasien yang ditujukan bagi pasien yang menjadi peserta BPJS berbasis komputer dan internet (Siagian, 2014).

Pengolahan data medis pasien JKN merupakan proses entry data medis pasien ke dalam P-Care. P-Care merupakan aplikasi dari BPJS Kesehatan untuk pengolahan data pasien JKN di fasilitas kesehatan tingkat pertama. Sebagai fasilitas kesehatan tingkat pertama yang bekerja sama dengan BPJS Kesehatan, Puskesmas Gondokusuman II juga menggunakan $P$-Care untuk pengolahan data pasien JKN. Data pasien JKN terdiri dari data sosial dan data medis. Untuk pengolahan data sosial sudah di-entry ke dalam $P$-Care oleh bagian penerimaan pasien. Sedangkan untuk pengolahan data medis pasien JKN akan diuraikan berikut ini.

Berdasarkan observasi yang dilakukan, diketahui bahwa petugas yang meng-entry data medis pasien JKN ke dalam $P$-Care adalah perawat, dokter, perawat gigi dan bidan yang berada di masing-masing balai pengobatan. Petugas menggunakan data hasil pemeriksaan pasien JKN yang tertulis pada rekam medis pasien sebagai sumber data untuk entry ke dalam P-Care. Rekam medis pasien JKN berisi anamnesis, diagnosis, terapi, dan identitas tenaga medis yang memeriksa pasien. Petugas di BP-KIA meng-entry data medis pasien JKN ke dalam $P$-Care menggunakan komputer yang tersedia di ruang BP-KIA. Sedangkan petugas BPU dan BPG menggunakan komputer di Laboratorium dan ruang Gizi untuk entry data medis pasien JKN ke $P$-Care secara bergantian. Hal ini dikarenakan komputer milik BPU dan BPG mati. Pengolahan data medis pasien JKN dilakukan dengan meng-entry hasil pemeriksaan pasien JKN ke dalam $P$-Care sesuai dengan petunjuk yang ada dalam P-Care. Entry data medis pasien JKN dilakukan setelah jam pelayanan pasien selesai. Berdasarkan observasi yang peneliti lakukan, diketahui bahwa langkah-langkah entry data medis ke dalam $P$-Care adalah sebagai berikut.

1) Pilih menu Entry Data, kemudian pilih submenu pelayanan pasien.

2) Memasukkan nomor pendaftaran pasien sesuai dengan nomor urut saat entry data sosial di $P$-Care untuk pencarian pasien. Jika pencarian pasien berhasil akan tampil isian data medis yang harus dimasukkan. 
3) Kolom isian data medis yang dimasukkan berupa keluhan, terapi, diagnosis, kesadaran, tinggi badan, berat badan, tekanan darah sistole dan diastole, respiratory rate, heart rate, tenaga medis dan status pulang. Namun mengingat tidak semua pemeriksaan pasien sesuai dengan daftar isian tersebut maka petugas hanya mengisi hasil pemeriksaan pasien berupa diagnosis pasien, tekanan darah untuk pasien yang beresiko darah tinggi, dan tenaga medis yang menangani, serta status pulang jika pasien dirujuk.

4) Untuk memasukkan diagnosis pasien, petugas memasukkan kata kunci ke dalam pencarian diagnosis. Kata kunci yang dimasukkan berupa istilah penyakit dalam bahasa Inggris. Hal ini dilakukan karena dalam $P$-Care semua diagnosis berupa bahasa Inggris. Setelah ditemukan diagnosis beserta kodenya, petugas memilik Apply untuk menyimpan diagnosis yang dipilih.

5) Setelah selesai pengisian semua data pelayanan, maka pilih simpan untuk menyimpan semua data pelayanan yang telah di-entry dalam P-Care.

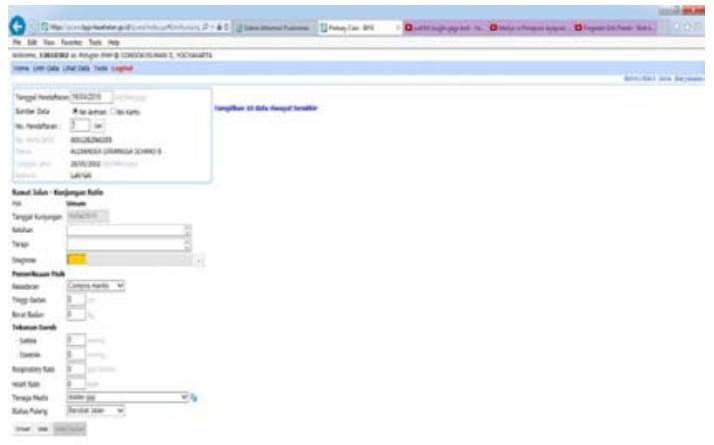

\section{9}

Gambar 1

Tampilan Pengisian Data Medis Pada P-Care

Masing-masing balai pengobatan di Puskesmas Gondokusuman II sudah meng-entry data medis pasien JKN ke dalam menu entry data pelayanan yang ada pada $P$-Care. Namun, belum semua data medis pasien JKN yang berobat ke Puskesmas Gondokusuman II dapat di-entry sampai ke dalam P-Care.

Berdasarkan hasil studi dokumentasi yang dilakukan peneliti dengan mencocokkan jumlah kunjungan pasien pada lembar laporan RJTP dengan data pada $P$-Care, terdapat beberapa data medis pasien JKN yang belum di-entry ke dalam menu entry data pelayanan. Dari 408 jumlah keseluruhan pasien JKN yang berkunjung pada 2-16 Maret 2015, baru 224 data medis pasien JKN yang berhasil di-entry ke dalam menu entry data pelayanan pada $P$-Care.

Selain entry data medis ke dalam $P$-Care, Puskesmas Gondokusuman II juga masih melakukan entry data medis pasien JKN ke dalam SIMPUS. SIMPUS ini digunakan untuk entry semua data medis pasien, baik pasien JKN dan pasien non JKN. Rekam medis dipisahkan antara pasien JKN dan pasien non JKN. Selanjutnya, data medis pasien JKN di-entry ke dalam $P$-Care yang merupakan aplikasi milik BPJS Kesehatan. Berdasarkan observasi yang dilakukan peneliti, langkah-langkah entry data medis ke dalam SIMPUS adalah sebagai berikut.

1) Pilih menu pemeriksaan, kemudian pilih submenu pemeriksaan sesuai balai pengobatannya. Misalkan BPU, maka pilih pemeriksaan umum.

2) Memasukkan kategori pencarian pasien, bisa menggunakan nomor rekam medis, nama atau alamat pasien.

3) Setelah itu, input data pasien berupa anamnesis, kode diagnosis, tindakan dan obat.

4) Jika ada rujukan maka, tujuan rujukan juga diinput ke dalam SIMPUS.

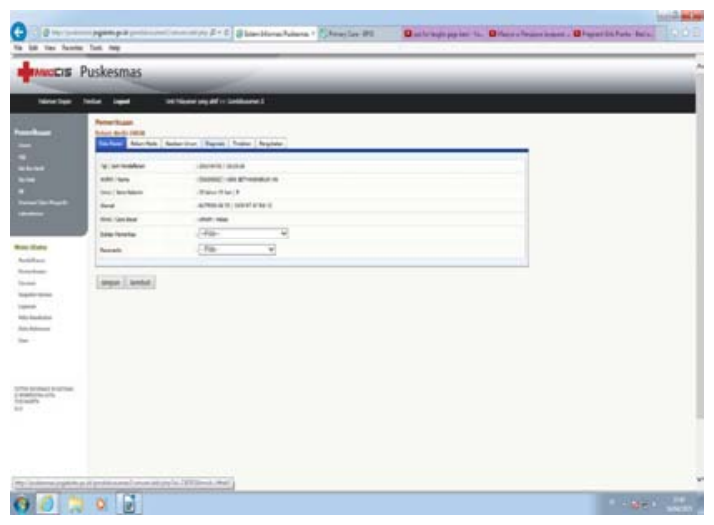

Gambar 2

Tampilan SIMPUS Untuk Input Data Medis Pasien

SIMPUS merupakan sebuah sistem informasi yang terintegrasi dan didesain multi user yang disiapkan untuk menangani keseluruhan proses manajemen Puskesmas. SIMPUS merupakan suatu perangkat lunak atau dalam istilah komputer adalah software yang fungsi utamanya untuk mengolah data pasien yang berkunjung ke Puskesmas (Banunaek, 2014). 
Berdasarkan Perjanjian Kerjasama Antara BPJS Kesehatan Cabang Utama Yogyakarta Dengan Pemerintah Kota Yogyakarta Tentang Pelayanan Kesehatan Tingkat Pertama Pada Puskesmas Di Kota Yogyakarta Bagi Peserta BPJS Kesehatan Nomor 41.A/PER.YK/2014, kewajiban Pihak Kedua (Dinas Kesehatan Kota Yogyakarta) salah satunya adalah merekam seluruh data pelayanan yang telah diberikan kepada Peserta melalui aplikasi fasilitas kesehatan tingkat pertama ( $P$-Care) yang diberikan Pihak Pertama (BPJS Kesehatan). Pemanfaatan $P$-Care merupakan salah satu indikator kualitas mutu dalam evaluasi dan penilaian penyelenggaraan pelayanan kesehatan bagi Peserta BPJS.

Berdasarkan teori di atas, Puskesmas Gondokusuman II juga telah melakukan pengolahan data medis pasien JKN setelah jam pelayanan selesai. Pengolahan data medis dilakukan dengan cara entry hasil pemeriksaan ke dalam $P$-Care dan SIMPUS. Puskesmas Gondokusuman II telah melakukan pengolahan medis pasien JKN sesuai dengan Perjanjian Kerjasama di atas, yakni merekam seluruh data pelayanan yang telah diberikan kepada Peserta melalui aplikasi fasilitas kesehatan tingkat pertama (P-Care) yang diberikan Pihak Pertama (BPJS Kesehatan), baik data sosial maupun data medis. Namun, dalam pelaksanaannya belum semua data medis pasien JKN di-entry ke dalam P-Care.

\section{Pelaporan Program JKN}

Pelaporan adalah salah satu fungsi manajemen berupa penyampaian pengembangan atau hasil kegiatan atau pemberian keterangan mengenai segala hal yang bertalian dengan tugas dan fungsi-fungsi kepada pejabat yang lebih tinggi, baik secara lisan secara tulisan (Rusdiana, 2014).

Menurut Sumarto dan Dwiantara (2000), laporan memiliki berbagai macam kegunaan dan mungkin sekali dari masing-masing kegunaan tersebut saling berkaitan satu sama lain. Adapun beberapa manfaat tersebut antara lain:

1) Sebagai sarana komunikasi vertikal;

2) Sebagai alat pertanggungjawaban;

3) Memberikan informasi penting;

4) Sebagai bahan untuk pengambilan keputusan.

Berdasarkan Perjanjian Kerjasama Antara BPJS Kesehatan Cabang Utama Yogyakarta Dengan Pemerintah Kota Yogyakarta Tentang Pelayanan Kesehatan Tingkat Pertama Pada Puskesmas Di
Kota Yogyakarta Bagi Peserta BPJS Kesehatan Nomor 41.A/PER.YK/2014, kewajiban Pihak Kedua (Dinas Kesehatan Kota Yogyakarta) salah satunya adalah membuat dan menyampaikan laporan bulanan kepada Pihak Pertama (BPJS Kesehatan) yang mencakup pencatatan atas jumlah kunjungan Peserta dan rujukan serta pelayanan lainnya yang diberikan kepada peserta.

Laporan yang dibuat Puskesmas Gondokusuman II sebagai bentuk pertanggungjawaban pelaksanaan program JKN adalah laporan kunjungan pasien JKN dan laporan 10 besar penyakit pasien JKN. Laporan tersebut dibuat berdasarkan jenis kepesertaan pasien, yakni Askes, Jamkesmas dan BPJS Mandiri.

Untuk pembuatan laporan, petugas biasanya menggunakan data pasien JKN yang ada dalam SIMPUS. Untuk laporan kunjungan pasien JKN, petugas mengambil data dari register harian pasien dengan disesuaikan jenis kepesertaanya, apakah Askes, Jamkesmas atau BPJS Mandiri dalam SIMPUS. Kemudian, petugas meng-copy data ke dalam Microsoft Excel dengan sesuai format laporan kunjungannya. Setelah itu, petugas melakukan verifikasi dengan mencocokkan data yang sudah diambil dari SIMPUS dengan data pasien JKN yang ada pada lembar laporan RJTP. Petugas kadangkadang juga menggunakan $P$-Care untuk cross-check data pasien JKN Sedangkan untuk laporan 10 besar penyakit pasien JKN, petugas mengambil data dari SIMPUS.

\section{Pendanaan Program JKN}

Puskesmas Gondokusuman II menjalankan program JKN sejak 1 Januari 2014. Dalam program JKN ini ada dua macam sistem pendanaan yakni sistem kapitasi dan sistem non kapitasi. Untuk sistem pendanaan kapitasi, Puskesmas Gondokusuman II akan menerima penggantian biaya pelayanan kesehatan sesuai dengan jumlah peserta yang terdaftar di Puskesmas Gondokusuman II setiap bulannya tanpa melakukan klaim terlebih dahulu. Sedangkan untuk sistem pendanaan non kapitasi, Puskesmas Gondokusuman II bisa melakukan klaim kepada BPJS Kesehatan untuk beberapa pelayanan yang tidak termasuk pelayanan kapitasi. Pelayanan non kapitasi tersebut antara lain pelayanan $\mathrm{ANC}$, ibu nifas, bayi, KB, ambulance dan beberapa pelayanan lainnya sesuai dengan ketentuan yang ada dalam MOU. 
Dalam sistem pendanaan non kapitasi, Puskesmas harus melakukan klaim kepada BPJS Kesehatan, persyaratan yang harus disertakan pada saat klaim adalah kwitansi pelayanan rangkap tiga dengan bermaterai cukup, fotokopi kartu JKN, daftar rekap pelayanan dan persyaratan lain yang tercantum dalam MOU. Namun, Puskesmas Gondokusuman II belum pernah melakukan klaim pelayanan non kapitasi kepada BPJS Kesehatan, misalnya pelayanan ANC.

Pendanaan kesehatan merupakan suatu cara dalam memungkinkan seseorang memenuhi kebutuhan medisnya (Hatta, 2011). Berdasarkan Permenkes RI Nomor 59 Tahun 2014 Tentang Standar Tarif Pelayanan Kesehatan Dalam Penyelenggaraan Program Jaminan Kesehatan, tarif pelayanan pada Fasilitas Kesehatan Tingkat Pertama meliputi tarif kapitasi dan tarif non kapitasi.

Berdasarkan Permenkes RI Nomor 59 Tahun 2014 Tentang Standar Tarif Pelayanan Kesehatan Dalam Penyelenggaraan Program JKN, tarif kapitasi adalah besaran pembayaran per-bulan yang dibayar dimuka oleh BPJS Kesehatan kepada FKTP berdasarkan jumlah peserta yang terdaftar tanpa memperhitungkan jenis dan jumlah pelayanan kesehatan yang diberikan. Tarif kapitasi diberlakukan pada FKTP yang melakukan administrasi pelayanan; pelayanan promotif dan preventif, pemeriksaan, pengobatan, dan konsultasi medis, tindakan medis non spesialistik, baik operatif maupun non operatif; pelayanan obat dan bahan medis habis pakai, termasuk pil dan kondom untuk pelayanan Keluarga Berencana; pemeriksaan penunjang diagnostik laboratorium tingkat pertama. Standar tarif kapitasi di FKTP ditetapkan untuk puskesmas atau fasilitas kesehatan yang setara sebesar Rp3.000,00 sampai dengan Rp 6.000,00.

Sedangkan berdasarkan Perjanjian Kerjasama Antara BPJS Kesehatan Cabang Utama Yogyakarta Dengan Pemerintah Kota Yogyakarta Tentang Pelayanan Kesehatan Tingkat Pertama Pada Puskesmas Di Kota Yogyakarta Bagi Peserta BPJS Kesehatan Nomor 41.A/PER.YK/2014, biaya pelayanan kesehatan rawat jalan tingkat pertama dibayarkan berdasarkan kapitasi perjiwa per-bulan sudah sudah termasuk pajak. Tarif kapitasi untuk masing-masing Puskesmas di Kota Yogyakarta sebesar 6000 rupiah. Pembayaran kapitasi kepada Puskesmas dilaksanakan setiap bulan selambat-lambatnya tanggal 15 bulan berjalan sesuai dengan ketentuan yang berlaku. Begitu juga yang terjadi di Puskesmas Gondokusuman II, untuk sistem pendanaan JKN secara kapitasi sudah berjalan sesuai dengan Perjanjian di atas. Dana kapitasi masuk ke Puskesmas Gondokusuman II tiap bulannya.

Kendala dalam pelaksanaan Program Jaminan Kesehatan Nasional Di Puskesmas Gondokusuman II terkait penerimaan pasien, pengolahan data medis, pelaporan dan pendanaan.

Dalam pelaksanaan suatu kegiatan sering kali menghadapi kendala yang dapat menyebabkan pelaksanaan suatu kegiatan tidak berjalan dengan lancar. Begitu juga dengan pelaksanaan program JKN terkait penerimaan pasien, pengolahan data medis, pelaporan serta pendanaan di Puskesmas Gondolusuman II masih ditemukan kendala dalam pelaksanaannya. Menurut Kemenkes RI (2014), elemen penilaian akreditasi Puskesmas antara lain adalah kajian terhadap masalah-masalah spesifik yang ada dalam proses penyelenggaraan pelayanan dan upaya Puskesmas untuk kemudian dilakukan koreksi dan pencegahan agar tidak terulang lagiBerikut ini kendala yang dihadapi Puskesmas Gondokusuman II dalam pelaksanaan program JKN dilihat dari 6M (man, materials, machines, mehods, markets dan money).

\section{Kendala pelaksanaan JKN dari segi man.}

Man atau sumber daya manusia merupakan kunci utama keberhasilan suatu organisasi. Dalam hal pelaksanaan JKN di Puskesmas Gondokusuman II, yang dimaksud man adalah petugas yang terkait dengan penerimaan pasien, pengolahan data medis, pelaporan dan pendanaan. Kendala yang muncul dari unsur man adalah sebagai berikut.

1) Petugas penerimaan pasien masih ada yang belum bisa megoperasikan komputer.

Dalam penerimaan pasien JKN, petugas penerimaan pasien harus melakukan pengecekkan kepesertaan pasien JKN di $P$-Care, entry data sosial pasien JKN pada $P$-Care dan SIMPUS menggunakan komputer. Berdasarkan hasil observasi yang dilakukan peneliti, masih ada dua petugas penerimaan pasien yang belum bisa mengoperasikan komputer. Petugas akan kesulitan ketika harus mengecek kepesertaan pasien JKN dan entry data ke dalam P-Care dan SIMPUS. Apalagi ketika petugas yang bisa mengoperasikan komputer sedang tidak ada di ruang penerimaan pasien. 
Dalam hal ini, petugas penerimaan pasien masih menggandalkan dua orang petugas yang bisa mengoperasikan komputer dalam pengecekkan kepesertaan pasien JKN dan entry data sosial pasien JKN. Hal ini dikarenakan petugas yang belum bisa mengoperasikan komputer memiliki tugas utama sebagai petugas kasir dan petugas filing. Meskipun tugas utama dari petugas yang belum bisa mengoperasikan bukan pendaftaran pasien, namun dalam pelaksanaannya semua petugas yang ada di penerimaan pasien bekerja secara fleksibel dan melakukan semua kegiatan yang ada di penerimaan pasien, mulai dari pendaftaran, kasir dan filing.

2) Petugas penerimaan pasien salah mengidentifikasi jenis kepesertaan pasien JKN.

Identifikasi jenis kepesertaan pasien JKN dilakukan oleh petugas penerimaan pasien. Petugas harus memastikan jenis kepesertaan pasien JKN, apakah pasien tersebut termasuk ke dalam pasien Askes, Jamkesmas atau BPJS Mandiri. Namun masih ada pasien JKN yang diidentifikasi tidak sesuai kepesertaannya. Misalnya, pasien Askes diidentifikasi sebagai pasien Jamkesmas, maka data pasien JKN yang ada di SIMPUS berbeda dengan data pasien JKN yang ada di lembar laporan RJTP.

Jika terjadi kesalahan identifikasi kepesertaan JKN, petugas pelaporan akan menggunakan bukti kunjungan yang telah ditandatangani oleh pasien JKN pada lembar laporan RJTP sebagai pedoman utama untuk membuat laporan kunjungan pasien JKN. Kemudian untuk laporan 10 besar penyakit tetap menggunakan data diagnosis pasien JKN yang ada pada SIMPUS .

3) Petugas pengolahan data medis mendapat tugas di luar Puskesmas Gondokusuman II.

Dalam proses pengolahan data medis pasien JKN, Puskesmas Gondokusuman II melakukan entry data sosial dan data medis ke dalam $P$-Care. Namun, belum semua data medis dapat di-entry ke dalam $P$-Care karena petugas mendapat tugas di luar Puskesmas seperti posyandu, penyuluhan dan rapat. Dalam hal ini, petugas di BPU melakukan pembagian tugas untuk proses entry data medis pasien JKN ke dalam P-Care, yakni ada satu perawat dan satu dokter. Sedangkan dua perawat BPU lainnya entry data medis pasien ke dalam SIMPUS.
Di BPG dan BP-KIA, entry data medis pasien JKN ke dalam $P$-Care maupun SIMPUS hanya dikerjakan oleh satu orang saja karena jumlah pasien JKN yang tidak banyak dibandingkan dengan BPU. Namun, ketika semua petugas pengolahan data medis mendapat tugas luar maka entry data medis ke dalam $P$-Care juga akan terganggu.

4) Petugas pengolahan data medis kesulitan dalam menentukan kode diagnosis penyakit pasien JKN.

Dalam pengolahan data medis pasien JKN. Salah satu data yang di-entry ke dalam P-Care adalah diagnosis. Diagnosis yang di-entry harus merupakan kode diagnosisnya. Di Puskesmas Gondokusuman II terkadang petugas belum bisa menentukan kode diagnosis karena tidak hafal kode, diagnosis pada $P$-Care menggunakan istilah bahasa Inggris. Selain itu, tidak semua diagnosis pasien JKN dalam kasus rujukan bisa di-entry ke dalam P-Care. Untuk kasus rujukan, kode diagnosis yang di-entry ke dalam $P$-Care harus disesuaikan dengan diagnosis yang diperbolehkan dirujuk.

Berdasarkan wawancara yang dilakukan peneliti diketahui bahwa pada saat terjadi permasalahan dalam menentukan kode diagnosis pasien JKN, petugas pengolahan data medis akan membuka catatan yang berisi daftar-daftar kode diagnosis. Selain itu petugas juga akan mengkonsultasikan lagi kepada dokter yang merawat pasien

5) SDM Puskesmas belum sepenuhnya mengetahui tata cara pendanaan JKN secara non kapitasi.

Untuk pendanaan program JKN secara non kapitasi, Puskesmas Gondokusuman II harus melakukan klaim kepada BPJS Kesehatan setiap bulannya. Namun, SDM yang ada di Puskesmas Gondokusuman II masih beranggapan bahwa semua Puskesmas rawat jalan hanya memperoleh pembayaran program JKN secara kapitasi saja. Hal ini dikarenakan peraturan pendanaan non kapitasi untuk puskesmas rawat jalan belum lama keluar. Selain itu, petugas juga belum memahami tata cara klaim pelayanan non kapitasi karena belum membaca MOU secara keseluruhan.

Meskipun demikian, Puskesmas Gondokusuman II pernah mencoba untuk melakukan rekap untuk pelayanan non kapitasi pada bulan Januari 
2015, tetapi sampai sekarang belum melakukan klaim kepada BPJS Kesehatan.

\section{Kendala pelaksanaan JKN dari segi materials.}

Kartu JKN merupakan salah satu persyaratan yang harus di bawa pasien JKN ketika berobat ke sarana pelayanan kesehatan. Berdasarkan hasil observasi yang dilakukan peneliti diketahui bahwa dalam kartu BPJS Mandiri sudah tertera fasilitas kesehatan tingkat pertama tempat pasien terdaftar. Namun, untuk kartu Jamkesmas dan Kartu Askes belum tertera fasilitas kesehatan tingkat pertama tampat pasien terdaftar. Petugas harus mengecek fasilitas kesehatan tingkat pertama tempat pasien Jamkesmas dan Askes melalui P-Care.

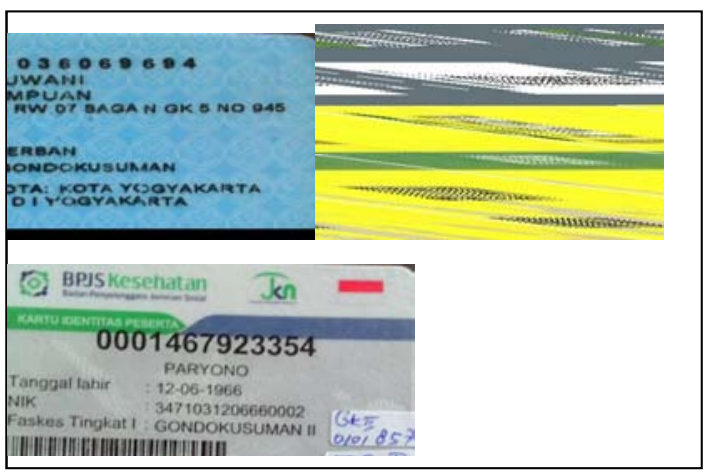

Gambar 3 Kartu JKN

Berdasarkan hasil observasi, untuk kartu Jamkesmas dan kartu Askes, petugas penerimaan pasien akan memberi label bertuliskan fasilitas kesehatan tingkat pertama tempat pasien terdaftar. Ketika P-Care error, label tersebut sangat membantu petugas untuk mengetahui dimana pasien JKN terdaftar dengan cepat tanpa harus konfirmasi kepada BPJS Kesehatan.

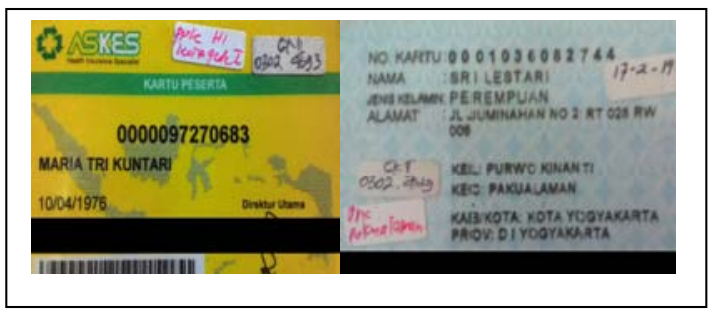

Gambar 4. Label Pada Kartu Jamkesmas dan Askes

\section{Kendala pelaksanaan program JKN dari segi machines.}

Machine yang dimaksud dalam pelaksanaan JKN ini adalah komputer, aplikasi P-Care dan SIMPUS yang digunakan untuk entry data pasien JKN.

\section{1) P-Care error}

Aplikasi $P$-Care digunakan untuk pengecekkan data kepesertaan, entry data sosial dan entry data pelayanan pasien JKN. Namun, berdasarkan observasi yang dilakukan oleh peneliti, diketahui bahwa aplikasi P-Care kadang error. Hal ini menyebabkan pengecekkan kepesertaan, entry data sosial dan entry data pelayanan pasien JKN tidak bisa dilakukan.

Berdasarakan hasil wawancara dinyatakan bahwa kendala yang dihadapi dari unsur mesin adalah $P$-Care error. Dengan begitu, Puskesmas Gondokusuman II tidak bisa melakukan pengecekkan kepesertaan, entry data sosial dan entry data pelayanan pasien JKN ke dalam P-Care.

Dalam permasalahan $P$-Care error, Puskesmas Gondokusuman II melapor kepada kantor BPJS Kesehatan dan diketahui bahwa P-care error karena server down.

Untuk kelangsungan pelayanan penerimaan pasien JKN, pengecekkan kepersertaan pasien JKN dapat dilakukan dengan konfirmasi kepada pihak BPJS Kesehatan melalui telepon untuk mengetahui fasilitas kesehatan tingkat pertama tempat pasien terdaftar. Namun hal tersebut memerlukan waktu yang lebih lama lagi dalam pelayanan pasien JKN.

Berdasarkan hasil wawancara dinyatakan bahwa petugas akan melakukan konfirmasi kepada pihak BPJS untuk melakukan pengecekkan kepesertaan pasien. Namun, jika pasien tidak mau menunggu konfirmasi dari BPJS Kesehatan, pasien JKN akan dilayani sebagai pasien umum.

Sedangkan untuk entry data tidak dilakukan oleh pihak Puskesmas Gondokusuman II ketika $P$-Care error. Jika $P$-Care sudah tidak error data pasien JKN tetap tidak di entry.

2) Komputer yang tidak bisa dioperasikan karena keterbatasan listrik.

Komputer merupakan hardware yang digunakan oleh petugas di masing-masing balai pengobatan 
untuk melakukan entry data pelayanan pasien JKN. Berdasarkan hasil wawancara, diketahui bahwa belum semua komputer di balai pengobatan dapat digunakan untuk entry data pelayanan pasien JKN. Komputer yang tidak dioperasikan adalah komputer BPU dan BPG. Untuk entry data pasien, petugas BPU dan BPG menggunakan komputer yang ada di laboratorium dan ruang gizi secara bergantian. Hal tersebut dikarenakan keterbatasan daya listrik yang ada di Puskesmas Gondokusuman II. Karena keterbatasan daya listrik terkadang juga menyebabkan listrik mati.

Untuk mengatasi permasalahan ini, Puskesmas Gondokusuman II sudah pernah menggunakan stavol agar komputer yang ada bisa digunakan untuk entry data pelayanan di masing-masing balai pengobatan. Namun penggunaan stavol belum bisa mengatasi permasalahan tersebut karena stavol terbakar.

3) SIMPUS belum sepenuhnya bisa digunakan untuk pembuatan laporan kunjungan, khususnya pasien BPJS Mandiri.

Dalam membuat laporan untuk program JKN, petugas menggunakan data dalam SIMPUS untuk proses pembuatannya. Namun, dalam SIMPUS tidak tersedia kolom nomor kepesertaan pasien BPJS Mandiri. Hal ini membuat petugas harus menulis sendiri nomor kepesertaan pasien BPJS Mandiri pada format laporan yang ada di Microsoft Excel.

Hasil wawancara juga sesuai dengan hasil observasi yang dilakukan peneliti dengan melihat item data pada SIMPUS, diketahui bahwa tidak tersedia kolom nomor kepesertaan pasien BPJS Mandiri. Dalam SIMPUS, jenis kepesertaan BPJS Mandiri diinput sebagai pasien kelompok khusus.

4) Belum terintegrasinya $P$-Care dengan SIMPUS. $P$-Care digunakan untuk pengolahan data pasien JKN, sedangkan SIMPUS digunakan untuk pengolahan semua kunjungan pasien termasuk juga pasien JKN. Di Puskesmas Gondokusuman II, belum ada integrasi antara P-Care dengan SIMPUS. Antara P-Care dan SIMPUS masih berjalan sendiri-sendiri. Dengan begitu, data pasien JKN akan di-entry ke dalam P-Care dan SIMPUS. Belum terintegrasinya $P$-Care dan SIMPUS juga akan menambah waktu yang dibutuhkan untuk pengolahan data pasien JKN. Untuk mengatasi belum terintegrasinya antara $P$-Care dengan SIMPUS, Puskesmas Gondokusuman II sudah menyampaikan kepada BPJS Kesehatan untuk mengintegrasikan antara $P$-Care dan SIMPUS. Dengan integrasi tersebut diharapkan dengan satu kali entry data pasien JKN sudah bisa memenuhi kebutuhan data pada SIMPUS maupun P-Care. Pengintegrasian antara $P$-Care dan SIMPUS juga harus memperhatikan keamanan data dan item-item data yang ada pada $P$-Care dan SIMPUS, misalnya kode diagnosis disamakan antara $P$-Care dan SIMPUS. Namun, sampai saat ini integrasi antara P-Care dan SIMPUS belum bisa dilakukan.

\section{Kendala pelaksanaan JKN dari segi methods}

Methods merupakan penetapan cara pelaksanaan kerja suatu tugas. Dalam pelaksanaan program JKN di Puskesmas Gondokusuman II, kendala dari segi methods adalah sebagai berikut.

1) Double entry data pasien JKN ke dalam P-care dan SIMPUS.

Belum terintegrasinya $P$-Care dengan SIMPUS, petugas juga harus harus bekerja dua kali dengan meng-entry data pasien JKN yang hampir sama ke dalam dua aplikasi yang berbeda, yakni $P$-Care dan SIMPUS. Petugas masih berusaha untuk meng-entry data pasien JKN ke dalam $P$-Care dan SIMPUS. Dengan jumlah pasien JKN yang di Puskesmas Gondokusuman II belum terlalu banyak, petugas masih bisa untuk melakukan entry data ke dalam $P$-Care maupun SIMPUS. Berbeda jika jumlah pasien JKN banyak maka akan memakan banyak waktu dan membebani petugas.

2) Belum adanya PKIK mengenai pelaksanaan JKN secara rinci.

Di Puskesmas Gondokusuman II, dalam melakukan penerimaan pasien berdasarkan pada prosedur kerja pendaftaran dan rekam medis sebagai pedoman petugas penerimaan pasien agar pelayanan pasien di unit pendaftaran dan rekam medis berjalan dengan tertib dan lancar. Berdasarkan studi dokumentasi pada PKIK Puskesmas Gondokusuman II, prosedur pelayanan unit pendaftaran dan rekam medis adalah sebagai berikut. 
a) Pasien datang ambil nomor urutan antrian;

b) Pasien menunggu panggilan;

c) Petugas memanggil pasien sesuai nomor urut antrian;

d) Petugas mendaftar sesuai keperluan pasien;

e) Petugas memberikan form isian data pasien;

f) Petugas membuat kartu tanda berobat dan resep sesuai data pasien;

g) Pasien dipersilahkan menunggu di poli tujuan pasien;

h) Petugas membuat rekam medis baru sesuai nomor indeks;

i) Petugas mengurutkan rekam medis pasien sesuai dengan nomor urut antrian;

j) Petugas mengantar rekam medis ke poli sesuai tujuan pasien.

Dalam penerimaan pasien JKN juga masih menggunakan prosedur kerja di atas. Petugas melaksanakan semua langkah yang ada dalam prosedur kerja pendaftaran dan rekam medis tersebut. Namun, terdapat langkah pelayanan pendaftaran pasien JKN yang belum terinci dalam prosedur kerja pendaftaran dan rekam medis di atas. Langkah tersebut adalah pengecekkan kepersertaan JKN dan entry data sosial pasien ke dalam $P$-Care maupun ke dalam SIMPUS. Meskipun belum tertulis dalam prosedur kerja, petugas sudah melakukan pengecekkan kepesertaan pasien JKN dan entry data sosial pasien JKN ke dalam P-Care dan SIMPUS. Hal ini dikarenakan ketentuan-ketentuan yang belum terinci dalam prosedur kerja sudah disampaikan secara lisan.

Sedangkan untuk pengolahan data medis, pelaporan dan pendanaan JKN tidak ada prosedur kerja ataupun instruksi kerja secara tertulis yang digunakan oleh petugas dalam melaksanakan kegiatan pengolahan data medis, pelaporan dan pendanaan.

Berdasarkan hasil wawancara kepada pertugas terkait pengolahan data medis, pelaporan dan pendanaan yang menyatakan bahwa tidak ada prosedur kerja secara tertulis yang digunakan sebagai pedoman dalam melakukan tugasnya.

a. Kendala pelaksanaan JKN dari segi markets.

Markets dalam pelaksanaan program JKN adalah pasien. Kendala yang terjadi dilihat dari segi market adalah kurang pahamnya pasien mengenai prosedur pelayanan pasien JKN.

Hal tersebut ditunjukkan dengan adanya pasien yang kurang paham mengenai penunjukkan fasilitas tingkat pertamanya. Sekarang ini, pasien JKN harus periksa sesuai dengan fasilitas tingkat pertama tempat pasien terdaftar.

Berdasarkan hasil wawancara dengan salah satu pasien JKN yang menyatakan bahwa pada saat mendapat kartu Jamkesmas, pasien tersebut hanya diarahkan untuk membawa kartu Jamkesmas yang dimiliki untuk periksa di manapun dan tidak mendapat informasi bahwa peserta JKN harus berobat sesuai dengan fasilitas kesehatan tempat pasien terdaftar. Berikut kutipan wawancaranya.

Pasien yang merupakan penduduk dalam Kota Yogyakarta juga ada yang melakukan komplain karena tidak bisa menggunakan KTP sebagai jaminan kesehatannya. Hal ini dikarenakan penduduk Kota Yogyakarta yang sudah terdaftar sebagai peserta JKN harus menggunakan jaminan tersebut di FKTP dimana pasien terdaftar. Jaminan KTP hanya bisa digunakan untuk penduduk kota Yogyakarta yang belum memiliki jaminan apapun.

Hasil di atas senada dengan pernyataan dari salah satu pasien JKN. Pasien JKN menyatakan tidak mengetahui bahwa penduduk Kota Yogyakarta yang sudah memiliki kartu JKN harus menggunakan kartu JKN untuk berobat di tempat pasien terdaftar dan tidak diperbolehkan menggunakan KTP sebagai jaminannya.

Dari permasalahan di atas, petugas penerimaan pasien akan memberikan penjelasan kepada pasien mengenai prosedur pelayanan JKN. Jika pasien JKN tidak terdaftar di Puskesmas Gondokusuman II, petugas akan mengarahkan pasien untuk kembali ke fasilitas kesehatan tempat pasien terdaftar atau dilayani sebagai pasien umum. Selain itu petugas juga akan mengarahkan kepada pasien yang tidak terdaftar di Puskesmas Gondokusuman II lapor kepada BPJS Kesehatan untuk pindah fasilitas kesehatan ke Puskesmas Gondokusuman II jika ingin tetap periksa sebagai pasien JKN.

Berdasarkan hasil wawancara, upaya yang dilakukan adalah menjelaskan mengenai perubahan sistem yang terkait dengan berlakunya JKN sejak tahun 2014 kepada pasien. Untuk pasien JKN yang tidak terdaftar di Puskesmas Gondokusuman II, maka petugas akan mengarahkan pasien ke fasilitas kesehatan tempat pasien terdaftar untuk 
mendapatkan pelayanan tingkat pertamanya. Jika pasien menghendaki periksa di Puskesmas Gondokusuman II petugas akan meminta pasien untuk meminta surat sekali periksa dari kantor BPJS Kesehatan atau pindah fasilitas kesehatan ke Puskesmas Gondokusuman II atau membayar sendiri tanpa menggunakan kartu JKN yang dimiliki pasien. Selain itu, petugas juga akan mengarahkan pasien yang merupakan penduduk Kota Yogyakarta dan sudah terdaftar sebagai peserta JKN untuk menggunakan fasilitas pelayanan kesehatan di fasilitas kesehatan pasien terdaftar.

Kartu JKN harus dibawa oleh pasien JKN ketika berobat ke Puskesmas Gondokusuman II. Namun, berdasarkan hasil wawancara diketahui bahwa belum semua pasien JKN membawa kartu kepesertaan JKN saat periksa di Puskesmas Gondokusuman II. Pasien yang tidak membawa kartu JKN, untuk sementara didaftar sebagai pasien umum.

Dalam hal pasien yang tidak membawa kartu JKN, petugas penerimaan pasien menyarankan pasien agar membawa kartu JKN untuk kunjungan berikutnya.

b. Kendala yang muncul dari segi money.

Money merupakan hal yang tidak kalah pentingnya dalam suatu organisasi. Uang harus disediakan untuk membiayai gaji tenaga kerja, alat-alat yang dibutuhkan dan harus dibeli, serta hasil yang akan dicapai dari suatu organisasi.

Berdasarkan wawancara dengan Responden Triangulai 4, dalam pelaksanaan program JKN di Puskesmas Gondokusuman II masih ditemukan kendala dari segi money. Kendala tersebut tidak hanya belum adanya anggaran untuk memperbaiki keterbatasan daya listrik yang ada di Puskesmas Gondokusuman II, tapi juga anggaran untuk intergrasi $P$-Care dan SIMPUS.

\section{SIMPULAN}

1. Penerimaan pasien JKN dimulai dari pengambilan nomor antrian, kemudian pengecekkan data kepesertaan, indentifikasi identitas sosial lainnya, entry data sosial ke dalam $P$-Care dan SIMPUS serta mengantarkan rekam medis ke balai pengobatan. Dengan harus entry data sosial ke dalam P-Care dan SIMPUS, maka waktu pelayanannya juga semakin lama.

2. Data medis pasien JKN di-entry ke dalam $P$-Care dan SIMPUS. Namun, belum semua data medis pasien JKN dapat di-entry ke dalam P-Care.

3. Pelaporan program JKN terdiri dari laporan kunjungan dan laporan 10 besar penyakit berdasarkan jenis kepesertaan pasien JKN, yakni Askes, Jamkesmas dan BPJS Mandiri. Laporan tersebut dikirim ke Dinkes Kota Yogyakarta setiap bulan.

4. Pendanaan program JKN ada dua macam, yakni berdasarkan kapitasi dan non kapitasi. Untuk kapitasi, Puskesmas menerima pembayarannnya setiap bulan. Sedangkan untuk non kapitasi, Puskesmas Gondokusuman II belum berjalan.

5. Kendala pelaksanaan program JKN terkait penerimaan pasien, pengolahan data medis, pelaporan dan pendanaan disebabkan oleh unsure 6M, yakni man, materials, machines, methods, markets dan money.

\section{DAFTAR PUSTAKA}

Abdelhak, M.; Grostick, S.; Hanken, M.A. (2011). Health Information: Management of A Strategic Resource. Sidney: WB. Saunders Company.

Agustina, I.E; Hastuti, A.P.; Mulyono, S. (2010). "Tinjauan Alur Prosedur Pelayanan Pasien Rawat Jalan Peserta Jamkesmas di RSUD Kabupaten Karanganyar”. Jurnal Kesehatan. Vol IV Nomor 2 [Internet]. Tersedia dalam http://ejurnal.stikesmhk.ac.id [Diakses pada 10 Juni 2015].

Arikunto, S. (2013). Prosedur Penelitian Suatu Pendekatan Praktik. Jakarta: PT Rineka Cipta.

Banunaek, N. (2014). "Sistem Informasi Puskesmas (SIMPUS)". Blog [Internet].Tersedia dalam http://nomensenbanuanek.blogspot.com [Diakses Pada 6 Juni 2015].

BPJS Kesehatan. (2014). "Bridging System Perpendek Antrean Pelayanan”. Buletin Info BPJS Kesehatan. Edisi X. Jakarta: BPJS Kesehatan.

Budi, S. C. (2011). Manajemen Unit Kerja Rekam Medis. Yogyakarta: Quantum Sinergis Media. 
Bungin, B. (2009). Penelitian Kualitatif: Komunikasi, Ekonomi, Kebijakan Publik, dan Ilmu Sosial Lainnya. Jakarta : Kencana.

Depkes RI. (1997). Pedoman Pengelolaan Rekam Medis Rumah Sakit di Indonesia.Jakarta: Depkes RI.

Hatta, G. R. (2011). Pedoman Manajemen Informasi Kesehatan Di Sarana Pelayanan Kesehatan. Jakarta. Universitas Indonesia (UI-Press).

IFHIMA. (2012). Education Module for Health Record Practice: Patient Identification, Registration and the Master Patient Index [Internet]. Tersedia dalam https://ifhima.files.wordpress.com [Diakses Pada 23 Januari 2015].

Kemenkes RI. (2014). Pedoman Pendampingan Akreditasi Fasilitas Kesehatan Tingkat Pertama. Jakarta: Direktorat Jenderal Bina Upaya Kesehatan.

(2014). Intrumen Akreditasi Puskesmas. Jakarta: Direktorat Jenderal Bina Upaya Kesehatan.

Moleong, L.J. (2013). Metodologi Penelitian Kualitatif. Bandung : Rosdakarya.

Muninjaya, A.A.G. (1999). Manajemen Kesehatan. Jakarta: EGC.

Notoatmodjo, S. (2012). Metodologi Penelitian Kesehatan: Edisi Revisi. Jakarta : Rineka Cipta.

Peraturan Menteri Kesehatan Republik Indonesia Nomor 5 Tahun 2014 Tentang Panduan Praktik Klinis Bagi Dokter Di Fasilitas Pelayanan Kesehatan Primer [Internet]. Tersedia dalam www.hukor.depkes.go.id [Diakses pada 28 Desembar 2014].

Peraturan Menteri Kesehatan Republik Indonesia Nomor 28 Tahun 2014 tentang Pedoman Pelaksanaan Program Jaminan Kesehatan Nasional [Internet]. Tersedia dalam www. depkes.go.id [Diakses Pada 16 Desember 2014].

Peraturan Menteri Kesehatan Republik Indonesia Nomor 59 Tahun 2014 Tentang Standar Tarif Pelayanan Kesehatan Dalam Penyelenggaraan Program Jaminan Kesehatan [Internet]. Tersedia dalam www.depkes.go.id [Diakses Pada 6 Desember 2014].
Peraturan Menteri Kesehatan Republik Indonesia Nomor 71 tahun 2013 Pelayanan Kesehatan Pada Jaminan Kesehatan Nasional [Internet]. Tersedia dalam www.depkes.go.id [Diakses Pada 16 Desember 2014].

Peraturan Menteri Kesehatan Republik Indonesia Nomor 75 Tahun 2014 Tentang Puskesmas [Internet]. Tersedia dalam www.depkes.go.id [Diakses pada 5 Juni 2015].

Peraturan Presiden Republik Indonesia Nomor 12 Tahun 2013 tentang Jaminan Kesehatan [Internet]. Tersedia dalam www.jkn.kemkes. go.id [Diakses Pada 6 Desember 2014].

Peraturan Walikota Yogyakarta Nomor 57 Tahun 2012 Tentang Penyelenggaraan Jaminan Kesehatan Daerah Kota Yogyakarta [Internet]. Tersedia dalam http:// hukum.jogjakota.go.id [Diakses pada 9 Juni 2015].

Perjanjian Kerjasama Antara BPJS Kesehatan Cabang Utama Yogyakarta Dengan Pemerintah Kota Yogyakarta Tentang Pelayanan Kesehata Tingkat Pertama Pada Puskesmas Di Kota Yogyakarta Bagi Peserta BPJS Kesehatan Nomor 41.A/PER.YK/2014.

Puskesmas Gondokusuman II. (2015). Profil Kesehatan Puskesmas Gondokusuman II Kota Yogyakarta Tahun 2014. Yogyakarta: Puskesmas Gondokusuman II

Rusdiana, H. A. (2014). Asas-asas Manajemen Berwawasan Global. Bogor: Pustaka Setia.

Rustiyanto, E. (2010). Statistik Rumah Sakit Untuk Pengambilan Keputusan. Yogyakarta: Graha Ilmu.

Undang-undang Nomor 24 Tahun 2011 Tentang badan Penyelenggara Jaminan Sosial Internet]. Tersedia dalam www.jkn.kemkes.go.id [Diakses Pada 6 Desember 2014].

Undang-undang Nomor 40 Tahun 2004 Tentang Sistem Jaminan Sosial Nasional [Internet]. Tersedia dalam www.jkn.kemkes.go.id [Diakses Pada 6 Desember 2014] 